\title{
Meta
}

Journal des traducteurs

Translators' Journal

\section{Brief guide to: Lynn Visson's FROM RUSSIAN INTO ENGLISH: An Introduction to Simultaneous Interpretation Why this book requires a "guide"}

\author{
VISSON, Lynn (1999): FROM RUSSIAN INTO ENGLISH: An \\ Introduction to Simultaneous Interpretation, Second Edition, \\ Focus Publishing, R. Pullins and Company, Newburyport MA, \\ xxi-213 p.
}

\section{Peter Kornakov}

Volume 46, numéro 3, septembre 2001

URI : https://id.erudit.org/iderudit/003343ar

DOI : https://doi.org/10.7202/003343ar

Aller au sommaire du numéro

Éditeur(s)

Les Presses de l'Université de Montréal

ISSN

0026-0452 (imprimé)

1492-1421 (numérique)

Découvrir la revue

Citer ce compte rendu

Kornakov, P. (2001). Compte rendu de [Brief guide to: Lynn Visson's FROM RUSSIAN INTO ENGLISH: An Introduction to Simultaneous Interpretation Why this book requires a "guide" / VISSON, Lynn (1999): FROM RUSSIAN INTO ENGLISH: An Introduction to Simultaneous Interpretation, Second Edition, Focus Publishing, R. Pullins and Company, Newburyport MA, xxi-213 p.] Meta, 46(3), 585-597. https://doi.org/10.7202/003343ar d'utilisation que vous pouvez consulter en ligne. 
VISSON, Lynn (1999): FROM RUSSIAN INTO ENGLISH: An Introduction to Simultaneous Interpretation, Second Edition, Focus Publishing, R.Pullins and Company, Newburyport MA, xxi-213 p.

Brief guide to: Lynn Visson's FROM RUSSIAN INTO ENGLISH: An Introduction to Simultaneous Interpretation

Why this book requires a "guide"

This book by Lynn Visson requires a "guide" for the benefit of readers who are not familiar with the Russian language, but who at the same time are interested in the general issues and difficulties surrounding simultaneous interpretation and the training of conference interpreters. The main hurdle facing such a reader is that Lynn Visson's book features a mixture of English and Russian texts (often without any translation from Russian into English). At the same time the book is useful not only to Russian-English conference interpreters but, to some degree, to anyone interested in the theory and practice of conference interpretation in general.

Comparisons are often made in specialist literature between the process of training conference interpreters and that of training future professional musicians or athletes. No-one would provide a complete novice with a cello and sheet music to Beethoven's Ninth Symphony, and ask them for a professional performance. Surprisingly enough, this is just what may happen to an unprepared or inexperienced bilingual who is asked to interpret (simultaneously or consecutively) just because they are bilingual. Lynn Visson discusses this comparison, illustrating it with the opinions of a number of high-ranking officials responsible for the interpreting services of the Administrative Office of the US Courts, (a frequent user of interpreting services), and of the US State Department (LV: xix-xx): "Contrary to what most people think, many interpreters are not bilingual [from childhood-pk], and many bilinguals are incapable of simultaneous interpretation. Some bilinguals cannot interpret the simplest of conversations. [...] That's about as true as saying that if you have two hands, you can automatically be a concert pianist." The second opinion is as follows: "Every day people walk in here who are totally bilingual [ from childhood-pk]—and are totally incapable of interpreting... They just can't do it.” These are the kind of linguistic 
guidelines Lynn Visson's book offers with respect to the training of Russian to English conference interpreters. The wealth of general practical recommendations given, as well as tips, rules and information, makes this book an extremely useful tool for all practising novice interpreters, including those with different language combinations, as well as for anyone else interested in the theory and practice of conference interpretation. However, the abundance of Russian words and quotations given without translation may cause such a general reader some difficulty in reading the text.

This book contains an introduction (11 pages), two substantial "parts," in turn divided into chapters, and concludes with endnotes, a bibliography and an annex, "Booth Behaviour," by Margaret Bowen et al. Lynn Visson's choice of Margaret Bowen's "Booth Behaviour" deserves a special mention. The list of practical tips for beginners in the booth contains many useful "DOs" and "DON'Ts." It is something which could have been expanded on by Lynn Visson, especially the section concerning technical equipment and interpreters' ethics.

An extended Introduction covers the following issues:

- History of Soviet-Russian-American bilateral contacts;

- General questions and problems in training conference interpreters;

- Bilingual person vs good interpreter, and

- Interpreting into and out of mother tongue.

Let us analyse some issues that arise after reading the Introduction.

Page xii features a comparative table, Translation vs Interpretation, that does not distinguish between simultaneous and consecutive interpretation. This can make it difficult for a novice interpreter to make a comparative analysis. LV does not offer her definition of these differences until page xiii: "There are basically two types of interpretation, simultaneous and consecutive. In consecutive the interpreter takes notes while listening to the speaker. When the orator pauses after a few sentences or paragraphs the interpreter, relying on his notes and memory, reads out a translation in the target language." Many would not agree with such a definition both insofar as it refers to "reading out" and in terms of the word "translation."

University-level training of professional interpreters and linguists in Soviet Russia and in the US is discussed later in the Introduction, on page Xv: "There are more teachers of English in the Soviet Union than there are students of Russian in the US." Figures are not provided for post-Soviet Russia.

Nor can I agree with the author's statement that (LV: xvi) "Here the emigre who arrived at a young age or an interpreter of Russian background naturally has an advantage over Americans for whom the language is acquired later." I myself have had the opportunity of meeting émigrés from the former USSR in the United States, whose "former" native language (Russian) had suffered significantly during those years of emigration. Changes (interference) were liable to strike at any level: vocabulary, idioms, grammar, and even intonation. On the other hand, it is unfair to compare, for example, a Russian bilingual émigré-who is already working professionally as a conference interpreter, with an American student who is only a beginner in Russian or is only just starting to master (the art of) conference interpreting. It is unfair to compare two unequal things. Of course if we were talking about highly professional bilingual conference interpreters (Russian and American/British), theoretically there would not be a significant difference between them. Both, if they are 
qualified professionals, must have a very high level - indeed proficiency - in both languages.

I make so much of this specific matter because in the Soviet Union in particular the idea existed that Soviet interpreters were the best in the world $æ$ as were our planes, watches, pocket calculators, missiles etc. (At the same time we in the USSR were joking that our pocket calculators were the biggest pocket calculators in the world and our watches were the fastest.) As for the interpreters, this idea of the supremacy of home-grown Soviet interpreters who would work in both directions (into and out of Russian) was, as we still believe today, important to Soviet leaders for purely political and ideological reasons: they did not trust anyone except "our own," "home-grown," "home-styled" and "home-accredited and approved" employees.

Lynn Visson's Introduction (LV: xvii) provides many examples taken from Soviet text-books illustrating emasculated and defective English produced by a number of Soviet translators and interpreters, e.g.: "He is always making some or other plans" or "Have you settled nicely in your hostel?," or even "But having visited the battle sites and learned about the appalling trials and sufferings, and the courage of the Soviet people, [the outstanding actor-this part was omitted by Lynn Visson-pk] Burt

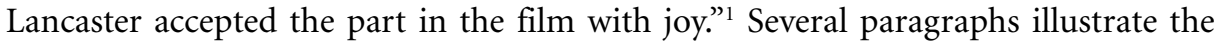
clumsiness of translation and interpretation from mother-tongue Russian into second-language English: "Serious grammatical errors, a limited vocabulary and halting delivery can make listening to interpretation into a foreign language an extremely tortuous process." (LV: xviii)

Part I of Lynn Visson's book is called Practical problems. The following main issues are analysed in Chapter I: The simultaneous interpreter: who he is and what he does:

- History of conference interpretation (mainly reformulating Gelii Chernov's view: Chernov: 1978, 3-8);

- Telephone ear;

- Description of work in the UN;

- Difficulties of simultaneous interpreting when you have a text in front of you;

- Working with slides/films;

- Booth behaviour and rules (in Bradford we call it "booth discipline") (see also LV: 212213);

- Interpreter adapting to speaker's accent, "nationality" and cultural background;

- Testing interpreter's nerves while working with Russian delegates and colleagues;

- What is longer: English-Russian or Russian-English interpretation, and why;

- Speed of delegate's delivery and speed of interpretation;

- Filling speaker's pauses;

- Local accents in Russian and phonetic difficulties;

- Lexical and grammatical difficulties when interpreting from Russian into English, and

- The motto: "Do not abandon your listener halfway!"

Let us proceed to some specific observations made after reading Chapter I.

The so-called "telephone ear" (Lynn Visson does not use this expression) is analysed on two occasions: firstly in Chapter I (p. 3) and secondly in Chapter XII (p. 124). The main idea is as follows: "While he [the interpreter-pk] is speaking the interpreter must simultaneously listen to his own voice and concentrate on the speaker... Some interpreters prefer to use only one earphone so that they can listen to themselves with the other ear; others prefer the security of two headphones." (LV: 
124) And earlier: "Learning to listen to oneself while concentrating on the speaker is crucial to successful interpretation.” (LV: 3)

This may be an appropriate point at which to reiterate that the actual process of training conference interpreters is a multifaceted and multilateral task. Coming back to the comparison with training athletes, one could say that their training involves body (muscles plus strategy), breathing (lungs plus strategy) and "head" (will, determination and mood). In some sense, an interpreter's training has much in common. I would single out at least two main differences in their training: linguistic and psycholinguistic. The first implies learning different strategies for reformulating the source text in the target language, taking into account its peculiarities of lexis, grammar, style and intonation, while the second is designed to master automatically such skills as listening and understanding in the source language, and reformulating the message in the target language whilst delivering the text in the target language without losing the new portion of the incoming text in the source language. Each skill can be automated using a range of training exercises that are, admittedly, based on linguistic material resources and sources. At the same time, the main value of this type of psycholinguistic training exercise is to develop important skills and abilities like attention, concentration and memory. Lynn Visson's book can be a very useful tool for the first aspect of training: linguistic. The other aspect is not analysed in her book and only a few tips are given, such as the "telephone ear" or the necessity of specific training for figures and names.

Beginners will find this book contains useful information concerning the "Van Doren" tactic - that is, working with a previously prepared translation of a speech. They will find fairly impartial comments on the extra difficulty of this triple splitting of attention: audio source (coming through headphones) plus written text (through the visual channel) plus monitoring one's own delivery.

A particularly important part of Chapter I opens with these words: "Booth behaviour has its own rules." (LV: 4-6) "As opposed to children, interpreters should be heard and not seen. (LV: 5)... The interpreter must try to adapt to the speaker's accent and take into account his nationality and cultural background, whether he is being ironic, dispassionate, or deliberately vague. No matter what he may think of the speaker or his ideas, while he is working the interpreter is that speaker, and must convince the listener that he is that person." (LV: 6)

Special attention is given here to the peculiarities of an interpreter's work with Russian delegates. Knowing the specific patterns can save an interpreter's nerves and energy: “The interpreter's nerves may also be tested by Russian delegates who monitor the interpretation and correct the interpretation... at other times, unfortunately, he may be showing off what he thinks is an excellent knowledge of English.”

Chapter I also encourages inexperienced young interpreters to approach the task artistically. Lynn Visson uses a quote from Robert V. Ekvall's memoir Faithful Echo "Interpretation at its best... is based on something very close to inspiration... We are nothing if not artists and we operate under terrific pressures. Those pressures, the sources from which they spring, and the interpreter's reaction to them have a very large place in the problem of interpretation." (Ekvall, 1960: 70-71)

In the part which deals with the peculiarities and specific difficulties of being an interpreter, Lynn Visson analyses both speedy and excessively slow delivery. The author provides some very interesting and persuasive ratio and correlation data comparing 
the length of Russian-English interpretation with that of English-Russian interpretation: "The English-Russian interpreter may have a harder time with a galloping speaker than does his Russian-English counterpart, since the sheer length of Russian words and the structure of the language make English-Russian interpretation thirtythree per cent longer than Russian-English. Regardless of how fast the speaker is going, however, it is of paramount importance that the interpreter finish or "wrap up" his sentences." (LV: 8) Later, on page 12, we find: "A Russian translator's injunction, 'Do not abandon your reader halfway' can be reworded for the interpreter as 'Do not abandon your listener halfway." Such examples of the 'golden rules' of conference interpretation can be found throughout the book. For example, on page 124: "Unless he has made a genuine contresens, the interpreter should avoid correcting himself... In front of the microphone, the interpreter cannot afford to be a perfectionist." It might be better if these 'golden rules' were presented all together in one paragraph.

Some researchers even call into question the very essence of the simultaneity of conference interpretation. They believe that the bulk of an interpreter's verbal work takes place during micro and macro pauses in the speaker's delivery. Lynn Visson quotes a Russian source (Shiriaev, 1979) that asserts that only 20-30\% of all the verbal work exceeds the limits of "simultaneity" i.e., is performed non-simultaneously.

Chapter II: How he works: the tricks of the trade focuses on the following issues and practical problems:

Editing:

- Condensing, and lexical and syntactical compression;

- $\quad$ Adding and expanding;

- Metonymy and synecdoche;

- Antonymic inversion, changing positives to negatives and vice versa, and

- Grammatical inversion and switching of grammatical categories.

"A flair for editing is particularly important for Russian-English interpreters," says Lynn Visson (LV: 15), "because Russian tends to be more verbose and English more condensed. Both the length of the individual words and the grammatical constructions make for longer phrases in Russian." Later she says (LV: 17): "While RussianEnglish interpretation tends to condense rather than to expand, English grammar and structure may require the addition of articles, auxiliaries or modals in compound tenses (e.g. we shall have been doing this) or pronouns and possessives: - She raised her hand' [in the original Russian text only two words 'raised hand' were used-pk]."

Special attention is given to various typical phenomena of Soviet and Russian life that often need fleshing out for clarification (LV: 17): "On Monday the Pioneers-members of the Soviet children's organization, or Young Communist leaguewere leaving for summer camp." As the author further remarks, "A literal translation, 'the pioneers went off to camp,' might convey some strange ideas of Wild West explorers visiting concentration camps."

As for antonymic inversion, it is a "very useful device for avoiding literal translation." Lynn Visson illustrates this with many examples, like "You mustn't say anything" instead of the more literal "You must be silent" or "This happens often" instead of "It happens not so seldom" (LV: 18). Here Lynn Visson offers a list of certain word combinations involving verbal negation which can easily be dealt with using antonymic inversion, for instance: "to take lightly" or "easy" instead of "not to take seriously." 
"Grammatical inversion and the switching of grammatical categories, translating a verb by a noun, a noun by a verb or an adjective by an adverb is another way of avoiding mot-à-mot interpretation." (LV: 19) Issues relating to syntactical inversion are analysed separately in Chapter X: Syntax.

Chapter III: Interpreting Cultures covers the following main issues:

- Cultural differences and words without translation or equivalents;

- Interpreter as cultural mediator, and

- Language in the service of Soviet Ideology: the labels "GOOD” and "BAD."

In this chapter Lynn Visson explains the "cross-cultural" differences and difficulties between "Communism" and "Capitalism" æ very common during the Cold War $æ$ in terms of vocabulary and "notions." She doesn't describe "communists" and "capitalists" in terms of being "Good" or "Bad," the only word she uses is "different."

Again, she encourages future interpreters with the following words (LV: 22): "The interpreter's role as a mediator between cultures as well as languages is of critical importance, and here his work is hardest and most rewarding... Hence the need in the interpreting field for 'mediating men' or 'persons with inter-cultural experiences.' The fact that cultural differences act as a block to understanding, however, is often blithely ignored by both conference participants and interpreters." I particularly liked an example taken from a Japanese-American meeting, after which it was said with the proper Japanese politeness: "You understood all the words correctly, but you didn't understand the silence between them." (LV: 22)

In this chapter the author offers a strategy for "vocabulary without equivalents" clearly shown in the following example: "He explained these ideas in his avtoreferat, the published summary of his thesis/dissertation" (LV: 26), where the purely Russian word avtoreferat - which has no English, French or Spanish equivalent - is used as it is and followed up with a brief explanation.

The very last page of Chapter III focuses on the hazards of cross-cultural mot-àmot rendition and of faux-amis - interpreter's "false friends." Strangely enough, Lynn Visson borrows the French expression mot-à-mot, but never faux-amis.

Chapter IV, Political Terminology, continues Lynn Visson's description of “Good” and "Bad" labels, this time in Politics. The entire chapter could easily be called "Manual of Language De-Ideologization." With a great deal of tact and measure the author introduces the reader to the following main points:

- Aggressiveness and offensiveness of Soviet Russian language illustrated with the excessive and abusive use of words such as "to fight," "sharp," "responsible," "irresponsible," "task," "serious" etc. etc. This lexical analysis has particular relevance for inexperienced interpreters just embarking on a career.

- Gorbachev's typical socio-political terminology.

The same chapter includes some excellent examples of editing work. I would like to quote just one of many (LV: 30-31):

Literal translation:

The Soviet Committee for the Protection of Peace, being the most mass Soviet nongovernmental organization, united in its ranks tens of millions of people.

This long Russian sentence is subjected to some editing: 
"The first four words can be reduced to 'The Soviet Peace Committee', 'being' here means 'as' and can safely be omitted. 'The most mass' is a fancy way of saying 'biggest' or 'largest'. 'Unites in its ranks' boils down to 'brings together' or 'unites'. 'Tens of millions' would be more idiomatic in English as 'dozens', but neither 'tens' nor 'dozens' is really necessary. The point is that a great many people are involved:

The Soviet Peace Committee, the largest Soviet nongovernmental organization, brings together millions of people."

Lynn Visson continues with a very precise calculation: "The original Russian text had 34 syllables, the literal rendering 44, and the reworked text 33." At the same time it is "both more idiomatic and saves eleven syllables, a considerable economy when a speaker is talking quickly."

As for Gorbachev's language, I would like to illustrate it for the reader's pleasure with a condensed example taken from the book (LV: 50): "What went before perestroika were years of stagnation. Russia had to be born in suffering, and reached an historic turning point. The process of perestroika was to be made irreversible, and had its pattern. People were confronted by a host of evils: all-permissiveness, all-forgiving attitude, idlers, parasites, loafers, hacks all acting with impunity, parochialism, regionalism and overdepartmentalization and narrow institutional interests..." This sentence could be continued if we had more space. Fortunately enough, the vast majority of today's Russian politicians and economists, state and cultural figures have managed to make the switch from old-style "Soviet" Russian to modern de-ideologized language.

Chapter V: Verbs and their Problems tackles the issues of Russian verbs as, "Russian verbs, with their limited tense system, aspects, prefixation, impersonal, participial and gerundive constructions, pose a large potential stumbling block for the interpreter." (LV: 51) It discusses the following main issues:

- Significant differences in grammar between the Russian and English verbal systems;

- The use of the verb to be in different tenses;

- Conditional sentences in Russian and English;

- Tenses and temporal forms;

- The mixed use of Perfective and Imperfective verbal forms in the same context;

- Russian morphology vs. English lexical means (delat' - sdelat' vs to do - to achieve), and

- Strategies for dealing with present active participles, verbal adverbs, verbs with complements (LV: 58): “Though students are traditionally taught that present active participles are translated [pk] by an -ing form, the interpreter can save time and words by using a prepositional phrase or short subordinate clause, or by dropping the participle: The group with such outstanding results is the pride of our institute."

Throughout this chapter the author offers a number of practical tips and wellillustrated strategies (LV: 57): "The interpreter should be alert to such [aspectual$\mathrm{pk}$ ] distinctions and should not hesitate to use quite different words-and tenses- to translate the members of an aspect pair. On the whole, however, the highly reduced Russian tense system causes Russian-English interpreters more problems than does aspect."

One of the main aims remains the same: to economise the interpreter's time, condensing where possible with grammatical and morphological tools (LV: 59): "The interpreter should be particularly sensitive to lengthy Russian verbal constructions 
which can be reduced to a word or two in English: to talk utter nonsense - 15 syllables in Russian vs 6 in English; to alphabetize - 13 Russian vs 5 English. A Russian verb and adverb or descriptive phrase may be condensed into a single verb: to glare - 4 Russian: 2 English; to bludgeon - 7: 3."

After a chapter on verbs comes Chapter VI: Yesterday, today and tomorrow: Time expressions, where Lynn Visson details a number of basic strategies and rules (LV: 61): “Time expressions often require a good deal of rethinking on the interpreter's part. Everyone knows that 'vchera vecherom' is not 'yesterday in the evening' but last night."

The main content of Chapter VII: SAYING “NO”: Negative constructions, could be summarized in these three blocks:

- Do not get sick again!

- Double negation.

- $\quad$ The power of positive thinking.

The next chapter deserves extensive commentary: Chapter VIII: Small and Slippery Words: conjunctions, prepositions and particles because, as Lynn Visson warns the reader, "Three categories of little words-conjunctions, prepositions and particles_can cause interpreters big problems." (LV: 69) Prepositions and cases with different meanings are analysed in this chapter. Such a scrupulous analysis is entirely justified as, "One study showed that errors in the use of prepositions accounted for $28 \%$ of all serious grammatical errors made by interpreters." (LV: 69 quoting Andrzej Kopczynski, Conference Interpreting: some linguistic and communication problems, Poznan: UAM, 1980) To illustrate the complexity of the problem, I have chosen just one Russian preposition "po" which can be translated into English in different contexts as under, about, along, down, up, across, on, throughout, all over, from, because of, on account of, for, in, according to, by, over, out of, at with all the subsequent pitfalls and hurdles this may present the interpreter (LV: 73). Particles and exclamations also form part of the body of this chapter.

Chapter IX: Numerals and Names could easily be expanded to match the size of the entire book because of its great difficulty and importance. There are several levels of difficulty when dealing with numerals and names interpreted from Russian into English. Psycholinguistic difficulty is one of these. Lynn Visson recalls that "during World War II suspected spies were ordered to solve dozens of math problems out loud in the hope they would break down and under the pressure of the figures reveal their native language and true nationality" (LV: 83). The author offers a number of useful well-illustrated strategies like taking notes or rounding. Individual attention is given to verbs and figures and phonetic difficulties. Among other important issues figure:

- Change of case: instrumental becomes nominative;

- Geographical names and proper names;

- Strategy for unknown towns, and

- Abbreviations and strategies for dealing with abbreviations.

Trainee conference interpreters will find useful guidelines such as (LV: 83): “The way to learn to interpret figures, therefore, is by listening rather than reading" or (LV: 84) "The way to interpret the number quickly and correctly is to write it down" and (LV: 84) "Whether 3,493 or 3,494 foreign students were enrolled last year in the University 
of Southern Patagonia may not be critical to world history. But the number of missiles destroyed or inspected, or the number of millions allocated to a government budget is not something the interpreter can pass over in silence-or fudge. In military and political negotiations figures mast be exact." The motto of this chapter is also to be found in the book: (LV: 84) "The goal is to listen intelligently [pk], using semantic context whenever possible."

"No matter how good an interpreter's choice of words, poor syntax can make him unintelligible," reminds Lynn Visson in Chapter X: Syntax (LV: 103), which deals with syntactical problems and presents the following main issues:

- Brief general description of Russian Syntax;

- Theme - Rheme in Russian;

- Theme - Rheme in Translation;

- Colloquial Russian and its "inverted" syntax, and

- Prepositions and cases.

Lynn Visson highlights the syntactical differences between the translated and the "interpreted" version of an English into Russian text. I would like to quote one of her many examples (LV: 97):

Interpreted text: What is fully justified is the conclusion... (close to the original) or Something that would seem fully justified is the conclusion drawn by the Secretary General in his recent report that ... while the translated text might sound like this: The conclusion made by the General secretary in his recent report... is/seems fully justified...

A particularly useful piece of advice is given on page 96: "To avoid committing himself to a rigid sentence structure at the beginning of a long sentence the interpreter can stall for time by using the very useful words 'something', 'that', or 'what' with the verb to be: Something which is extremely dangerous is terrorism.

What is extremely dangerous...

That which is extremely dangerous is..."

To conclude this chapter the author summarizes (LV: 102-103): "In dealing with the huge problems posed by Russian syntax the interpreter must (to use an old Soviet metaphor) make use of his entire arsenal of devices. He mast be careful not to jump in too fast and find himself bogged down in a hopelessly awkward sentence. The interpreter should acquire the habit of... if necessary dividing excessively lengthy sentences into two or even three short ones. Oblique initial objects should be turned into subjects... Written translation is an extremely useful training device for the simultaneous interpreter, since the restructuring of various syntactic patterns opens up choices and possibilities which can be put to good use in the high-pressure conditions of the booth." I would add only one further suggestion to this: trainee interpreters must build up their own list of classified strategies for dealing with different syntactical structures and ascertain which are more frequent and cover more cases.

"To some extent, stylistics is the icing on the interpreter's cake, for producing exact stylistic equivalents in addition to listening, absorbing, finding correct lexical items and restructuring sentences, may be asking too much.” (LV: 105) Chapter XI: High and Low: The Problem of Style covers the following main issues:

- The problem of borrowed words in Russian: “Today English is exerting a strong influence on both spoken and written Russian, and English borrowings have become part and parcel of the language of finance, computers, and the media." (LV: 105) 
- "Anti-grammatical” colloquial Russian.

- How typical is negation in Russian.

- Multi-stage examples of different styles well illustrated by the author (LV: 108):

Neutral:

Colloquial:

Too colloquial/vulgar:

Equivalent but archaic in English:

- Good and Bad lexically.

- Nouns and Adjectives.
They set no store by

They care nothing for

They couldn't care less about

They don't give a damn about

They don't give a brass farthing for

They don't give a tinker's dam ${ }^{2}$ for

As Lynn Visson remarks (LV: 105), "Russian written statements tend to fit into categories of style much more neatly than English texts, although in the last few years since the collapse of the Soviet system the boundaries between [the three main - pk] styles have become much more fluid." She offers several strategies, for example:

-(LV: 108): "If the interpreter is not $100 \%$ clear as to the speaker's precise intent and tone, a neutral expression is preferable to a highly colored one."

-(LV: 109): "Elevated language with Church Slavonic roots can be rendered on an appropriate stylistic level by using words with Latin roots... 'Low' colloquial Russian language can be rendered on a suitable stylistic level by giving preference to Anglo-Saxon roots."

I particularly liked her way of organising synonyms as rows (LV: 110-112): “The interpreter should constantly be on the alert for more synonyms to expand his repertory and stylistic range. A few examples for such mindstretching:

\section{countless/myriad/numberless/infinite \\ deftly/skilfully/nimbly/agilely/aptly/cleverly \\ unmask/expose/bare/reveal/bring to light.}

On page 110 Lynn Visson offers a short list of positive (Good) and negative (Bad) "things" arranged again as rows of synonyms. Here are some examples from that list:

\section{huge/enormous/colossal/vast/significant/considerable gloomy/sinister/dark/somber/black.}

Lynn Visson also proposes several strategies to deal with sayings and proverbs (LV: 112-113): "If a Russian proverb has no English equivalent the interpreter may provide a literal translation in the hope that listeners will accept this as one more example of quaint Russian customs and the mysterious Russian soul, e.g. 'If a woman gets off the cart it's easier on the horse.' If time allows the interpreter can add an explanation-'Or, as we say in English, good riddance/one less headache/one less problem/to think about." At the same time, warns Lynn Visson (LV: 113), "Ironically enough, those proverbs and sayings which seem to have perfect English equivalents contain particularly dangerous pitfalls. The interpreter who seizes on 'a pig in a poke' may bitterly regret his flash of brilliance if the speaker's cat [in Russian it is 'to buy a cat in a bag'- pk] then proceeds to meow or arch its back—or climb a tree." The biggest help she offers the trainee interpreter is to give him a hand with some useful strategies, for instance (LV: 113) "the interpreter can say 'he drinks like a fish—or as we say in Russian, like a shoemaker." Coming back to the example with a cat in a bag: "They 
want us to buy a cat in a bag or, as we say in English, a pig in a poke.” The interpreter should be careful not to make a distinctly Russian proverb sound specifically American - or any other nationality. Because of the widespread use of proverbs and idioms in Russian, it may sometimes happen that the interpreter is not familiar with one of them. Lynn has an answer to this eventuality too: "In the worst of all possible worlds - when the interpreter has not understood a single word of the Russian proverb-he can simply say, 'And in my country we have a proverb appropriate to this occasion.' Full stop." (LV: 113)

Towards the end of Chapter XI the author offers a list of 90 idioms and almost 60 proverbs (LV: 114-117) which can serve as a useful support for any language student learning Russian.

Another component Lynn Visson does not overlook is intonation, important because, as she remarks on page 119, "Russian and English intonational patterns are extremely different." Therefore a very short, condensed chapter (personally, I would make it longer) is dedicated to Intonation, Delivery and Training (Chapter XII). "The interpreter who unconsciously or consciously begins to mimic the rise and fall of Russian intonational patterns in English may sound jerky and singsong, as if he is making fun of the speaker. He must transform Russian intonation into English intonation in the same way that he transforms the lexical components of a Russian sentence into English." (LV: 119)

The brief description and linguistic analysis of Russian intonational constructions, called IK, from the point of view of their importance for trainee conference interpreter occupies five pages (pp. 119-123).

The importance of delivery is given special attention by the author (LV: 123): "Insofar as possible, the subject and verb should be kept close together, prepositions and their objects should not be unduly separated, and verbal noise such as 'uh-uh', heavy breathing, and coughing should be avoided... Staccato, rapid-fire, machine gun-monotonous delivery should be avoided."

Lynn Visson formulates, as usual, a number of strategies and guidelines for the interpreter (LV: 124-128):

- No matter how boring or obnoxious he finds the subject—or the speaker-he must not let personal feelings influence his delivery.

- There is no reason to repeat a phrase just because he has found a perfect-instead of adequate-adjective.

- If he feels that he has lost a critical word or phrase the interpreter can summarize an entire sentence rather than blindly spouting out a literal translation of half of it.

- He should chop excessively long sentences [very common in my language-pk] into digestible units, listen carefully for nouns and verbs, and cut back on strings of adjectives.

Who, if anyone, has no chance of ever becoming a good interpreter? Do we have to be born as conference interpreters or can we be trained? These are the sorts of questions Lynn Visson tackles in this chapter. She lists a number of clear obstacles to success in the profession, like memory problems, the inability to code switch, perfectionism and "translatoritis," stage fright, speech defects, a strong regional or foreign accent, stuttering, hoarseness and hearing problems among others. A person with the necessary abilities who wants to become a professional interpreter will need special training. Training will be particularly effective for those who have a "flair for code switching and an excellent knowledge of source and target languages." (LV: 124) 
Lynn Visson provides information on training course and schools for conference interpreters (Russian - English), such as Monterey (USA), Geneva, Paris, London, MISTI (Moscow) and others.

Chapter XII poses a crucial question concerning training: who should teach interpreting? Lynn Visson believes that "just as only an actor can truly teach acting, only an interpreter can truly understand all the problems interpreters face" in addition to being familiar with modern teaching methods. (LV: 125)

In this chapter trainee interpreters will find an answer to their question How and where to start? Lynn Visson considers that shadowing and paraphrasing with selfrecording can serve as a good start for self-training. If no tape with speeches is available she says, recordings of articles can be used (page 126). I would beg to differ with this last assertion bearing in mind the nature of the Russian press, a written genre which differs from the oral style on many levels: vocabulary, syntax (including word order), complexity and density, to name but a few differences.

The only notion of Lynn Visson's I find hard to comprehend is her theory to the effect that "the only way to learn to interpret is by interpreting" (p. 125). She offers so many techniques and useful strategies that contradict her idea of "learning interpreting by interpreting" that I can only hope it is simply a matter of "terminology." As far as I am concerned, the main strengths and assets of Lynn Visson's book lie in the fact that she teaches the student interpreter to work with both source and target language creatively. I would add to her sentence "... by interpreting," the words "using the full range of possible techniques outlined in this book," or something to that effect. In that case I would be happy.

I would like to conclude my brief guide to this first part of Lynn Visson's book with one more quotation which I see as crucial (LV: 127): "Above all, the student interpreter (the book is addressed to him or her) should be concerned with making sense."

Chapter XIII provides an extensive (11-page) selection of Conference terminology in both languages (Russian and English) prepared by the author.

PART TWO occupies one third of the book and offers selected practice texts and vocabulary from the UN. It seems to me that Part Two of the book lacks a number of important elements. Sub-sections is one of these: for example, abbreviations could have been presented in a sub-division of their own rather than appearing in little clusters within each block.

At the same time the reader will observe a large number of orthographic mistakes (misprints) in the Russian texts. In general I would say that, if the purpose of the book-especially Part Two-is for the student's practical work, there are very few texts for self-training, nor do these come with a translation (useful for checking against).

The second half of Part Two is called Selected vocabulary (featuring both languages), and is arranged by subject-matter: interpreting, political systems, disarmament, social system, women's issues, religion, education, economics, business, finance, the law, computers and electronics, medical, environment, outer space, media, art and museums, theatre and movies, films, music, sports, hunting, fishing, escorting delegations, greetings, introductions, meeting a visitor, hotel registration, sample toasts, etc. 


\section{Conclusion}

As a professional conference interpreting teacher at MA university level (University of Bradford, West Yorkshire, UK) I will be advising my future students to use this book by Lynn Visson as one of their main reading materials for Russian-English "linguistic" training. Furthermore, I hope the book will find a grateful audience not just among specialists in this specific field of conference interpretation (from Russian into English), but among all manner of readers interested in the problems of simultaneous interpretation.

Peter Kornakov

University of Bradford, Bradford, West Yorkshire, UK

\section{NOTES}

1. G.I.Pyadusova (1988: 181)

2. One of my English-native PG students told me that she was "very surprised about this as we usually hear 'tinker's cuss[curse]'."

\section{REFERENCES}

Chernov G., Teorija i praktika sinkhronnogo perevoda, Moscow, Ed.: Mezhdunarodnyje otnoshenija, 1978 (in Russian)

Ekvall Robert V. (1960) Faithful Echo, New York: Twayne.

Pyadusova G.I. Posobie po perevodu dlya lits, govoryaschikh na anglijskom jazyke, Moscow, Ed.: Russkij Yazyk, 1988 (in Russian).

ShiRIAev A.F. Spetsializirovannaja rechevaja dejatelnost (psikholingvisticheskoje issledovanije na materiale sinkhronnogo perevoda), Avtoreferat dissertatsii, Moscow, 1979 (in Russian). 